\title{
Hybrid-stabilized silver nanoparticles and their biological impact on hospital infections, healing wounds, and wheat cultivation
}

\author{
Tatyana B. Zheltonozhskaya ${ }^{\mathrm{a} *}$, Nataliya M. Permyakova ${ }^{\mathrm{a}}$, Tetiana O. Kondratiuk ${ }^{\mathrm{b}}$, \\ Tetyana V. Beregova ${ }^{\mathrm{b}}$, Valeriy V. Klepko ${ }^{\mathrm{c}}$, Bogdan S. Melnik ${ }^{\mathrm{d}}$ \\ ${ }^{a}$ Faculty of Chemistry, Taras Shevchenko National University of Kyiv, 60 Volodymyrska Street, \\ 01033 Kyiv, Ukraine \\ b Scientifically-Educational Center "Institute of Biology and Medicine”, Taras Shevchenko \\ National University of Kyiv, 64/13 Volodymyrska Street, 01601 Kyiv, Ukraine \\ ${ }^{c}$ Institute of Macromolecular Chemistry, NAS of Ukraine, 48 Kharkovskoye Shosse, \\ 02160 Kiev, Ukraine \\ ${ }^{\mathrm{d}}$ Scientific-Reseach Center of "Kernel”, 3 Taras Shevchenko Lane,01001 Kyiv, Ukraine \\ zheltonozhskaya@ukr.net
}

Keywords: polymer/inorganic hybrid, silver nanoparticles, structure, morphology, biological impact.

The structure and morphology of new biocide compositions based on silver nanoparticles and silica/polyacrylamide hybrids, as well as their diverse biological effects on traditional hospital infections and wound healing and winter wheat cultivation, were studied. The compositions showed a high bactericidal effect against bacteria of the genera Staphylococcus and Pseudomonas, and fungistatic effect against the yeast genus Candida and filamentous fungi of the genera Aspergillus, Cladosporium, Penicillium, Exophiala, and Fusarium. They also showed high activity in wound healing in rats and significantly changed the rate of development of winter wheat plants due to presowing treatment of seeds.

\section{Introduction}

Traditional biocide preparations for medicinal, industrial or everyday applications (antibiotics, disinfectants, preservatives, etc.) are based mainly on organic substances that are toxic for humans and the environment and can cause different allergic reactions, adverse effects and resistance [1-5]. The surface of the body and especially wounds of different nature are the environments for the development of numerous bacteria, such as gram-positive Staphylococcus spp. (42.7 \%) and gramnegative Pseudomonas aeruginosa (10.3\%) [6]; they can also be infected with yeast (Candida albicans) and filamentous fungi, as well as associations of microorganisms [7]. The 
causative agents of hospital infections exhibit significant virulence and resistance to antibacterial drugs. Therefore, biocidal preparations of a new generation, including metal nanoparticles with broad antibacterial, antiviral and antifungal action, are of particular interest [8-10]. It is very important that microbial cells, as a rule, are less able to show resistance to these "nanobiocides" or "nanoantibiotics" [11]. In addition, such biocidal preparations are more tolerant to human cells [12]. Recently, nanoparticles of metals or their oxides have also become actively used in the practice of growing agricultural plants instead of the corresponding metal salts or chelates $[13,14]$. This allows the long-term supply of metal ions that stimulate plant growth and additionally have a biocidal effect on various plant pathogens [15].

Silver nanoparticles (AgNPs) are known to be one of the most active biocides among various nanometals [16,17]. Due to their excellent antimicrobial potential, AgNPs are among the most commercialized nanoparticles that are widely used as therapeutic agents, household goods, as well as components of textiles and cosmetics $[18,19]$. At the same time, the cyto- and genotoxicity of these nanoparticles in vitro and in vivo, as well as their distribution in living organisms after administration, are intensively investigated. The toxicity of AgNPs is the result of the combined action of nanoparticles and silver ions released from the oxidized surface of the particles [20]. The internalization of AgNPs by mammalian cells occurs mainly by the mechanism of endocytosis [21]. The silver nanoparticles themselves and the $\mathrm{Ag}^{+}$-ions they release can interact with sulfur- and phosphorus-containing biopolymers, such as proteins and DNA, thus potentially causing cell damage $[22,23]$. The observed cytotoxicity of AgNPs is also expressed through the generation of reactive oxygen species (ROS) [24]. Increased oxidative stress can inhibit cell proliferative activity and induce genetically programmed cell death (apoptosis) or necrosis [24,25]. It was shown that the cytotoxicity level of AgNPs significantly depends on many factors, such as cell types [21,24], size and dose of nanoparticles $[26,27]$, nature (and size) of the "corona" of nanoparticles [28-31], and temperature [21]. But of particular interest is the effect of gradual full functional recovery of cells (such as normal human lung fibroblasts) from the AgNP-induced stress, first demonstrated in the study [21].

Earlier we have shown that grafted polymer/inorganic hybrids (PIH), including silica nanoparticles $\left(\mathrm{SiO}_{2}\right)$ and grafted polyacrylamide chains (PAAm), are effective nanoreactors for in situ synthesis of silver nanoparticles in an aqueous medium [32]. They provide a high rate of AgNPs formation, high yield of nanoparticles and their long-term stabilization in solution. It was suggested that the strong retention of silver ions and then the 
resulting AgNPs in hybrid matrices is due to the presence of silica "core" with a weakly negatively charged surface [32]. In addition, these hybrids contain nontoxic biocompatible components; therefore, it can be assumed that their compositions with AgNPs can be actively used in biomedicine. Such compositions may also be promising in agriculture because of the ability of PAAm chains in hybrids to decompose in the fields under atmospheric conditions [33].

There are numerous studies devoted to biocide effect of silver nanoparticles stabilized with synthetic and natural polymers [10,34-38]. At the same time, biocidal properties of AgNPs in a composition with silica/polyacrylamide hybrids have not been studied.

In the current work, we synthesized AgNPs in PIH solutions as templates, determined the morphology of the composition and size of nanoparticles, and then studied the biological impact of this composition on a number of bacterial and fungal cultures, which are traditional hospital infections. The ability of the composition to heal wounds and influence the growth of winter wheat plants has also been studied.

\section{Experimental part}

Synthesis and characterization of PIH.

We synthesized PIH by a free-radical grafting polymerization of acrylamide (AAm) "from" the surface of silica hydrosol, as in the study [32]. For this, we used Aerosil A-175 from "Orisil" (Ukraine) with a specific surface area of $1.82 \cdot 10^{5} \mathrm{~m}^{2} \cdot \mathrm{kg}^{-1}$, cerium (IV) ammonium nitrate (CAN) from "Aldrich" (USA) and AAm from "Merck" (Germany), which was recrystallized from chloroform. To prepare a silica hydrosol, the Aerosil suspension was stirred in deionized water with $\mathrm{C}=100 \mathrm{~kg} \cdot \mathrm{m}^{-3}$ during 24 hours and then centrifuged twice at $6000 \mathrm{rpm}$. The concentration of silica sol in the supernatant was measured by the gravimetric method, and the average nanoparticle size $\left(\mathrm{R}_{\mathrm{SiO}_{2}}\right)$ was determined by static light scattering, as in the study [39]. The weight ratios: $\left[\mathrm{Ce}^{\mathrm{IV}}\right] /\left[\mathrm{SiO}_{2}\right]=0.2$ and $\left[\mathrm{Ce}^{\mathrm{IV}}\right] /[\mathrm{AAm}]=7.7 \cdot 10^{-3}$, which determined the quantity and length of the grafted chains, and the concentration of $\mathrm{C}_{\mathrm{SiO} 2}=2.7 \mathrm{~kg} \cdot \mathrm{m}^{-3}$ were used. The reagents were mixed in an inert atmosphere at $293 \mathrm{~K}$ for 24 hours. The gel-like product was diluted, precipitated with acetone, re-dissolved in water and freeze-dried.

A detail structure of the hybrid was established by elemental analysis, dynamic thermogravimetric analysis (DTGA) and viscometry. Using elemental analysis data for $\mathrm{C}$ and $\mathrm{N}$, the weight fraction of PAAm (WPAAm= 0.852).in PIH was determined. The weight part of water $\left(\mathrm{w}_{\mathrm{H}_{2} \mathrm{O}}=0.053\right)$ was found according to DTGA as weight loss by a hybrid sample before the destruction beginning. Based on these results, the weight fraction of $\mathrm{SiO}_{2} \quad\left(\mathrm{WSiO}_{2}=\right.$ 0.095) was calculated.

To determine the number and molecular weight of the grafted PAAm chains, the aqueous 
$\mathrm{PIH}$ solution was kept for one week at $\mathrm{pH}=11.5$ and room temperature. It is well-known that under such conditions complete degradation (dissolution) of silica nanoparticles occurs [40] and only a slight hydrolysis of PAAm acrylamide units can be observed $[41,42]$. The reaction mixture then was re-precipitated with acetone and dissolved in water. The degradation products were completely separated from the polymer chains by dialysis of the solution against deionized water, and the average molecular weight of the grafts $\left(M_{\mathrm{vPAAm}}\right)$ was determined using the method of viscometry.

The viscosity was measured in diluted aqueous solutions of PAAm ( $\mathrm{C}_{\mathrm{PAAm}}=0.1-1.0$ $\left.\mathrm{kg} \cdot \mathrm{m}^{-3}\right)$ at $\mathrm{T}=303 \pm 0.1 \mathrm{~K}$ in the presence of $\mathrm{NaNO}_{3}\left(\mathrm{C}_{\mathrm{NaNO}_{3}}=1 \mathrm{M}\right)$ as a low molecular weight electrolyte to suppress possible polyelectrolyte effect caused by partial hydrolyses of acrylamide units. We used the Ostvald-type viscometer with the water-salt expiration time $\tau_{0}=93.5 \mathrm{~s}$. The resulting linear dependence of the reduced viscosity of polymer solution on its concentration was used to determine the intrinsic viscosity $([\eta])$ and to calculate the viscosity-average molecular weight of PAAm using relation (1) [43]:

$$
[\eta]=3.73 \cdot 10^{-2} \cdot M_{v P A A m}^{0.66},
$$

where $[\eta]$ was expressed in $\mathrm{cm}^{3} \cdot \mathrm{g}^{-1}$.

The obtained characteristics made it possible to calculate the number of PAAm grafts $(\mathrm{N})$ per one $\mathrm{SiO}_{2}$ nanoparticle according to the formula (2):

$$
N=\frac{4 \pi \cdot R_{S i O 2}^{3} \cdot \rho \cdot w_{P A A m} \cdot N_{A}}{3 \cdot w_{S i O 2} \cdot M_{v P A A m}}
$$

Here $\rho=2.1 \mathrm{~g} \cdot \mathrm{cm}^{-3}$ is the density of silica, the product $4 / 3 \pi \cdot \mathrm{R}_{\mathrm{SiO} 2}{ }^{3} \cdot \rho$ is the weight of one silica nanoparticle, $\mathrm{N}_{\mathrm{A}}$ is the Avogadro number. The results of calculations are shown in Table 1.

Table 1. The main parameters of the hybrid

\begin{tabular}{|c|c|c|c|}
\hline Sample & $\mathrm{R}_{\mathrm{SiO}_{2}, \mathrm{~nm}}$ & $\mathrm{M}_{\mathrm{vPAAm}}, \mathrm{kDa}$ & $\mathrm{N}$ \\
\hline $\mathrm{PIH}$ & 7.7 & 1588 & 14 \\
\hline
\end{tabular}

In situ synthesis of silver nanoparticles.

To obtain a stable composition of AgNPs/PIH, we performed in situ reduction of silver nitrate with sodium borohydride in a hybrid aqueous solution, as in the study [32]. An eight-fold molar excess of $\mathrm{NaBH}_{4}$ was used to achieve the complete conversion of $\mathrm{Ag}^{+}$-ions to zero-valent state at $\mathrm{C}_{\mathrm{AgNO}_{3}}=1.82 \cdot 10^{-2} \mathrm{~kg} \cdot \mathrm{m}^{-3}$ [44]. Hybrid solution with $\mathrm{C}_{\mathrm{PIH}}=2.0 \mathrm{~kg} \cdot \mathrm{m}^{-3}$ was mixed with $\mathrm{AgNO}_{3}$ and kept in a dark box for 30 minutes. Then a reducing agent was added and a yellow color appeared, reflecting the occurrence of AgNPs. Earlier, we showed that the formation of nanoparticles in this system was fully completed after 24 hours [32]. To separate the reaction by-products, we reprecipitated the AgNPs/PIH composition by ethanol and re-dissolved it in water.

The formation of AgNPs was confirmed by UV-Vis spectroscopy. The extinction spectrum of an aqueous mixture of $\mathrm{AgNO}_{3}$ with 
$\mathrm{PIH}$ was recorded in a quartz cell $\mathrm{l}=1 \mathrm{~cm}$ long in the region of 200-1000 nm using a Cary 50 Scan UV-Vis spectrometer from "Varian" (USA).

Additional confirmation of the appearance of AgNPs in the composition was obtained using wide-angle X-ray scattering (WAXS). For this purpose, the composition was cast from aqueous solutions $\left(\mathrm{C}_{\mathrm{PIH}}=2.0\right.$ and $\left.\mathrm{C}_{\mathrm{AgNO}_{3}}=3.64 \mathrm{~kg} \cdot \mathrm{m}^{-3}\right)$ into a Teflon mold placed in a dark box, and then dried in air and in a vacuum desiccator. The WAXS profile was obtained in a $2 \mathrm{~mm}$ thick cell using a DRON-2.0 X-ray diffractometer with $\mathrm{Ni}$ filter in a primary beam. Monochromatic $\mathrm{Cu}-\mathrm{K}_{\alpha}$ radiation with $\lambda=0.154$ $\mathrm{nm}$, filtered by Ni, was provided by an IRIS M7 generator (at an operating voltage of $30 \mathrm{kV}$ and a current of $30 \mathrm{~mA}$ ). The scattering intensities were measured with a scintillation detector scanning with a step of $0.2^{\circ}$ in the range of scattering angles $2 \theta=3-45^{\circ}$. Diffraction curves were reduced to equal intensities of the primary beam and to equal scattering volume according to the technique described in studies $[32,45]$.

\section{Studies of the composition morphology.}

The morphology of pure $\mathrm{PIH}$ and its composition with AgNPs in aqueous solutions was determined using transmission electron microscopy (TEM). Corresponding TEM images were obtained on a JEM-I23O instrument (JEOL, Japan) operating at an accelerating voltage of $90 \mathrm{kV}$. Small drops $\left(\sim 1 \cdot 10^{-4} \mathrm{~cm}^{3}\right)$ of solutions of a pure hybrid and composition in deionized water $\left(\mathrm{C}_{\mathrm{PIH}}=1 \mathrm{~kg} \cdot \mathrm{m}^{-3}\right)$ were applied to copper grids coated with Formvar films and carbon; they were then dried in air for $\sim 1-2 \mathrm{~min}$ and in a vacuum desiccator for 24 hours.

\section{Biological experiments.}

Standard microbiological agar nutrient media were used to characterize the effect of the AgNPs/PIH composition on the growth of bacterial and fungal cultures. The bacteria Staphylococcus aureus ATCC 25923, Escherichia coli, and Pseudomonas aeruginosa ATCC 27853, yeasts Candida albicans and filamentous fungi, such as Aspergillus ustus 165 FCKU, Cladosporium shpaerospermum 312 FCKU, Fusarium oxysporum 150 FCKU, and black yeast-like fungus Exophiala alcalophila 304 FCKU from the collection of microscopic fungi of Taras Shevchenko National University of Kiev (international acronym of collection is FCKU), were used as test cultures. In these experiments, we used both the initial composition and fragments of sterile cotton fabric $(30 \times 30 \mathrm{~mm})$ treated with this biocidal preparation.

The effect of AgNPs/PIH composition on test cultures was studied by diffusion in agar (disc method for bacteria and agar-hole method for filamentous fungi), assessing the presence or absence of a zone of inhibition of the growth of microorganisms around the disc or well of the agar and its diameter. In control experiments, an aqueous solution of the well-known biocidal preparation of benzalconium chloride $(\mathrm{C}=30 \mathrm{~kg}$ $\mathrm{m}^{-3}$ ) and fragments of cotton fabric moistened 
with sterile distilled water were used. The density of colony forming units (CFU) of microorganisms, such as cells or spores, in various experiments corresponded to $10^{6}-10^{8}$ $\mathrm{CFU} \cdot \mathrm{cm}^{-3}$. The cell content in the bacterial suspension $\left(1.5 \cdot 10^{8} \mathrm{CFU} \cdot \mathrm{cm}^{-3}\right)$ was determined using a densitometer of Vitek-2 microbiological analyzer (Bio Merieux, France). The number of spores of filamentous fungi in suspension $\left(1 \cdot 10^{6}\right.$ $\mathrm{CFU} \cdot \mathrm{cm}^{-3}$ ) was determined using a Goryaev camera.

To examine the ability of $\mathrm{AgNPs} / \mathrm{PIH}$ composition to heal wounds, 4 groups of rats of 10 each were used. Skin $10 \times 10 \mathrm{~mm}$ in size was removed on the back of each rat, and the resulting wounds obtained were treated with equal volumes of various preparations. The exception was the 1-st control group, in which wound healing occurred naturally without any treatment. We measured the wound area of rats at different time intervals using not only the AgNPs/PIH composition $\left(\mathrm{C}_{\mathrm{AgNPs}}=1.2 \cdot 10^{-2} \mathrm{~kg} \cdot \mathrm{m}^{-}\right.$ $\left.{ }^{3}\right)$ but also the commercial preparation Carbopol, which promotes wound healing, and an aqueous solution of eumelanin $\left(\mathrm{C}_{\mathrm{EM}}=1 \mathrm{~kg} \cdot \mathrm{M}^{-}\right.$ ${ }^{3}$ ) produced by black yeasts Pseudonadsoniella brunnea 470 FCKU [46]. The last preparation, EM, was able to increase the body's defenses [47] and, therefore, accelerate wound healing. Conducting these experiments, we followed the International Guiding Principles for Scientific Research Involving Animals (CIOMS, Geneva, 1985) and Directive 2010/63/EU of the
European Parliament and of the Council of 22 September 2010 as to protection of animals used for scientific purposes [48].

In the final biological experiments, winter wheat seeds belonging to the Arctis variety were treated with the $\mathrm{AgNPs} / \mathrm{PIH}$ composition immediately before sowing. For this purpose, the original composition (1:1) with $\mathrm{C}_{\mathrm{AgNP}}=1.2 \cdot 10^{-2} \mathrm{~kg} \cdot \mathrm{m}^{-3}$ and diluted 10 times (1:10) was used. Two $50 \mathrm{~kg}$ portions of winter wheat seeds were treated with $250 \mathrm{~cm}^{-3}$ of every composition. The treated seeds were planted and grown on the fields of "Kernel" Research Center during 2018 year.

\section{Results and discussion}

The fact of the AgNP formation in an aqueous $\mathrm{AgNO}_{3} / \mathrm{PIH}$ mixture at the addition of a reductant was confirmed by the appearance of a surface plasmon resonance band (SPRB) in the UV-Vis spectrum (Figure 1).

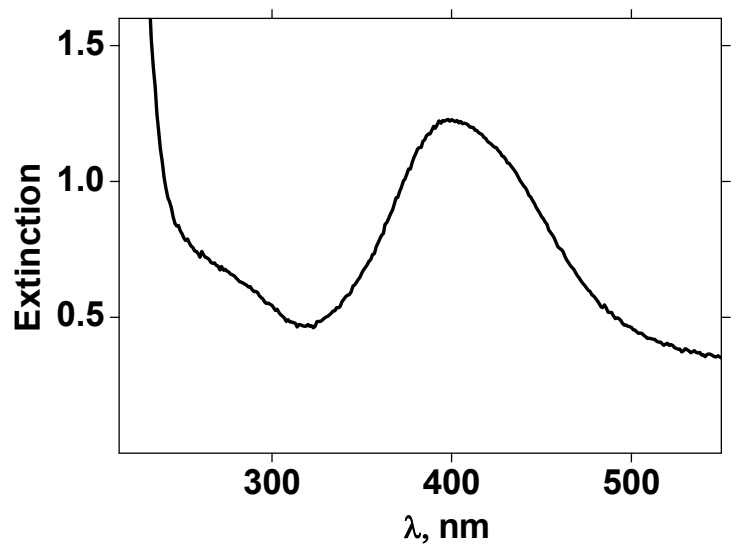

Figure 1. The extinction spectrum of the $\mathrm{AgNO}_{3} / \mathrm{PIH}$ composition $90 \mathrm{~min}$ after the introduction of $\mathrm{NaBH}_{4}$. $\mathrm{C}_{\mathrm{PIH}}=2.0 \mathrm{~kg} \cdot \mathrm{m}^{-3} ; \mathrm{C}_{\mathrm{AgNO} 3}=1.82 \cdot 10^{-2} \mathrm{~kg} \cdot \mathrm{m}^{-3} ; \mathrm{T}=20^{\circ} \mathrm{C}$.

The monomodal form of SFRP and its position in the spectrum $\left(\lambda_{\max }=400 \mathrm{~nm}\right)$ indicated the 
formation of spherical AgNPs with a size much smaller than the wavelength of light $(\mathrm{d}<30 \mathrm{~nm})$ $[49,50]$. Kinetic features of this process were discussed in detail earlier [32].

The presence of crystalline AgNPs in the dried composition was established by WAXS. The results (Figure 2) showed that the bulk structure of the compositions contained a polymere amorphous phase, which was displayed in WAXS profiles by two diffuse overlapping maxima at $2 \theta \sim 15^{\circ}$ and $21^{\circ}$, and crystalline Ag nanoparticles, which was confirmed by the presence of an intense crystalline silver peak (111) at $2 \theta \sim 38^{\circ}$ [51].

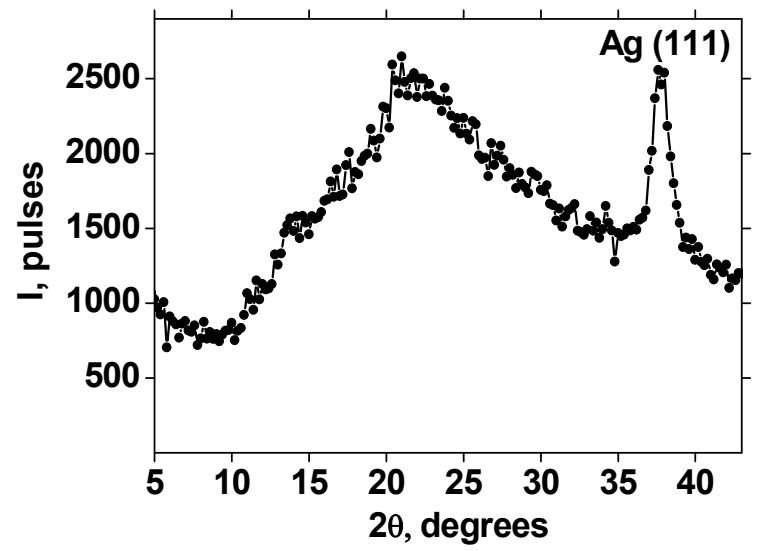

Figure 2. The intensity of wide-angle X-ray scattering $v s$ the scattering angle for the AgNPs/PIH composition. $\mathrm{T}=20^{\circ} \mathrm{C}$.

The appearance of this peak indicated the presence of crystalline AgNPs with a tetragonal face-centered cubic lattice [50].

Morphology of PIH in aqueous medium is shown in Figure 3 (a, b). The main elements of its structure are small nanoparticles with
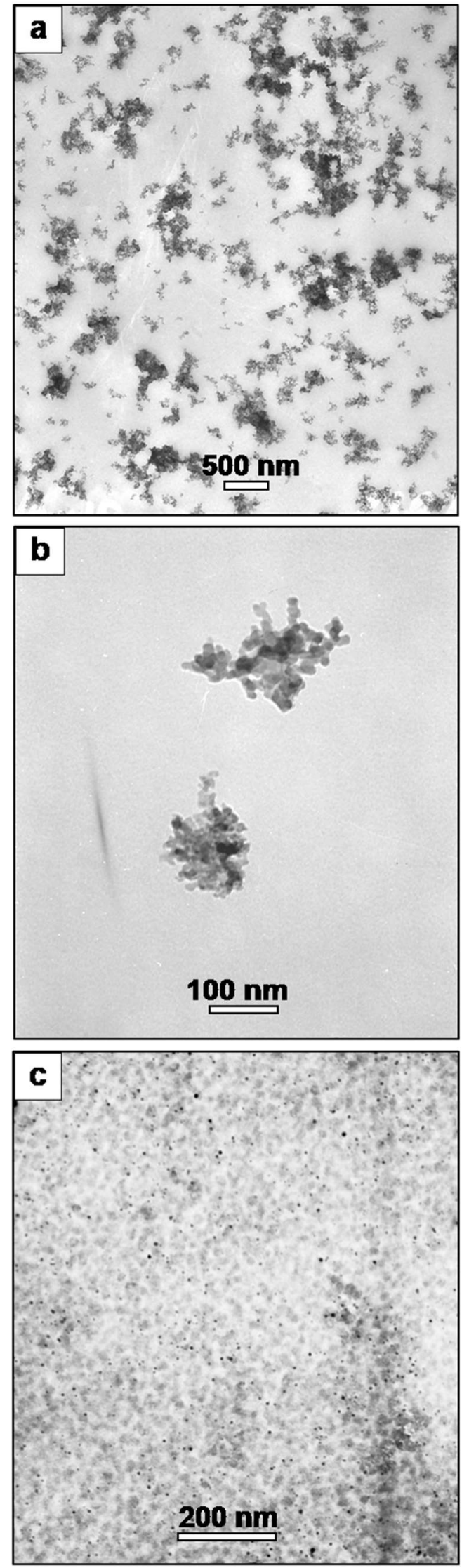

Figure 3. TEM images of: (a, b) pure PIH and (c) the composition of $\mathrm{AgNPs} / \mathrm{PIH}$ in aqueous solution. $\mathrm{C}_{\mathrm{PIH}}=1$ $\mathrm{kg} \cdot \mathrm{m}^{-3}, \mathrm{C}_{\mathrm{AgNPs}}=1.156 \cdot 10^{-2} \mathrm{~kg} \cdot \mathrm{m}^{-3}, \mathrm{~T}=20^{\circ} \mathrm{C}$. 
a size of $\mathrm{d}=6-18 \mathrm{~nm}$. TEM images demonstrate both individual nanoparticles and their fractal aggregates of various shapes and sizes. The reason for such developed aggregation of nanoparticles in an aqueous solution can be explained by the nature of the grafted chains in PIH. Indeed, it is known that PAAm forms various types of hydrogen bonds in an aqueous medium: along each polymer chain and between adjacent polymeric chains [52]. Being grafted to $\mathrm{SiO}_{2}$ nanoparticles, PAAm chains also form a system of hydrogen bonds with the silica surface [53]. Partial adsorption of PAAm chains on the $\mathrm{SiO}_{2}$ surface and their intra- and intermolecular interactions in the grafted layer lead to a relatively compact structure of PIH nanoparticles.

The situation changes dramatically after in situ synthesis of AgNPs in PIH solution. Significant changes in the morphology of PIH in the composition with AgNPs are observed (Figure 3 c). Hybrid nanoparticles containing one or more AgNPs swelled up to d 10-40 nm and significantly separated from each other. This meant that the synthesis of AgNPs ocurred previously in the grafted layer; therefore, PAAm chains were partially desorbed from the $\mathrm{SiO}_{2}$ surface and swelled in solution. Thus, the AgNPs/PIH composition can be represented as a set of individual particles of the following structure (Figure 4). A size of spherical AgNPs in the composition varied in the range $\mathrm{d}=3-9 \mathrm{~nm}$ (Figure 3 c).

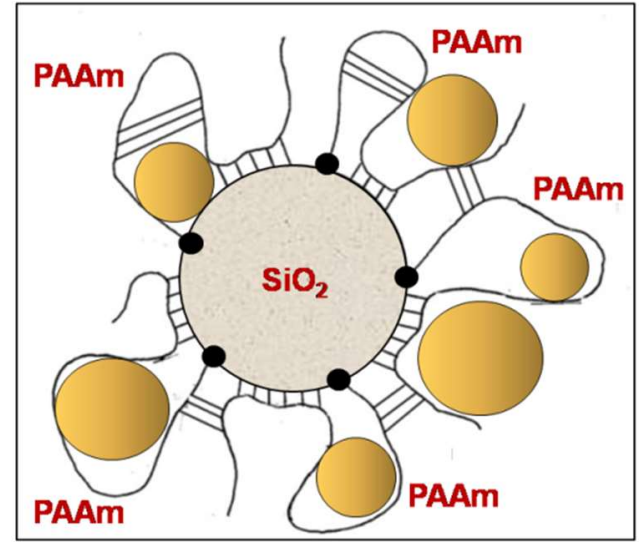

Figure 4. Schematic structure of individual particles of the AgNPs/PIH composition.

A series of microbiological tests showed that aqueous solutions of the AgNPs/PIH composition exhibit biocidal and biostatic effects of different degrees with respect to the gram-positive and gram-negative bacteria, yeast and filamentous fungi used. Examples of the impact of the initial composition and its dilutions $10(1: 10)$ and $100(1: 100)$ times on the bacterial cultures of Staphylococcus aureus and Pseudomonas aeruginosa are presented in Figures 5 and 6.

The biocidal effect of the composition with $\mathrm{C}_{\mathrm{AgNPs}}=1.2 \cdot 10^{-2} \mathrm{~kg} \cdot \mathrm{m}^{-3}$ and its diluted solutions (1:10 and 1:100) was detected in relation to both of the above bacterial cultures. Indeed, zones of growth inhibition after 24 hours corresponded to $7,10-12$ and $11 \mathrm{~mm}$, respectively, in the case of Staphylococcus aureus (Figure 5 a, b) and 9-10, 11-13 and 11$12 \mathrm{~mm}$ in the case of Pseudomonas aeruginosa (Firure 6 a). The biocidal effect persisted for the next 3-5 days (Figure 5 b, d and Figure 6 b), that is, it had a long-lasting character. 


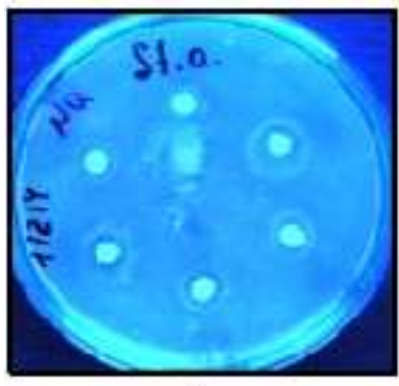

a

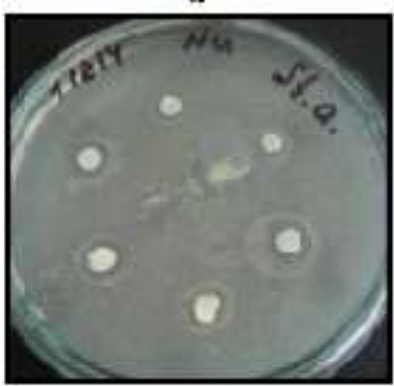

c

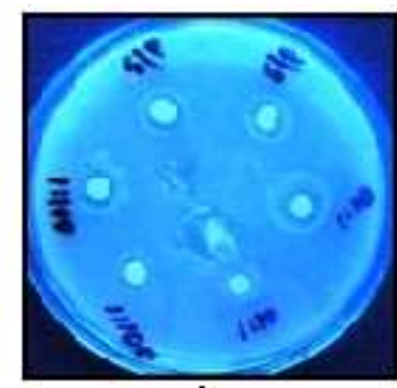

b

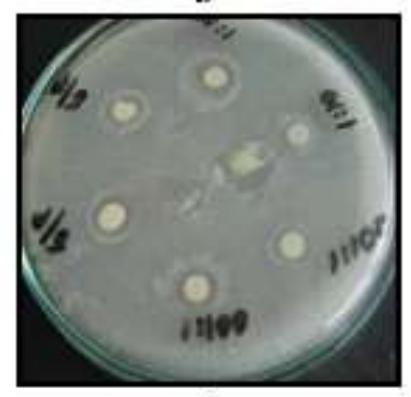

d

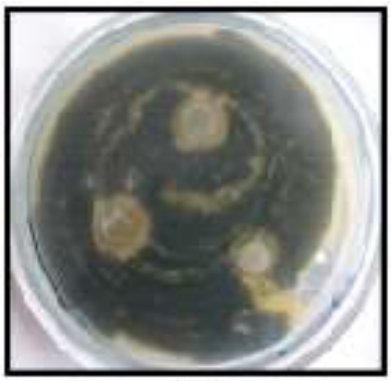

a

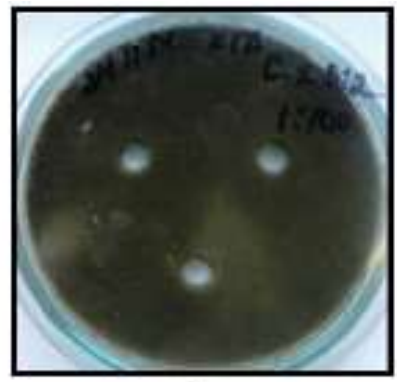

b

Figure 7. Zones of growth inhibition of Cladosporium sphaerospermum (top view) under the influence of (a) the initial composition and diluted 100 times (b) after (a) 5 and (b) 9 days. $\mathrm{T}=28^{\circ} \mathrm{C}$.

For these cultures, zones of growth inhibition were $14-15$ and 12-13 $\mathrm{mm}$, respectively.

Figure 5. Zones of growth inhibition of Staphylococcus aureus under the influence of the initial and diluted compositions after (a, b) 24 hours and (c, d) 4 days. (a, c) Top view and $(\mathbf{b}, \mathbf{d})$ bottom are shown. $\mathrm{T}=35^{\circ} \mathrm{C}$.

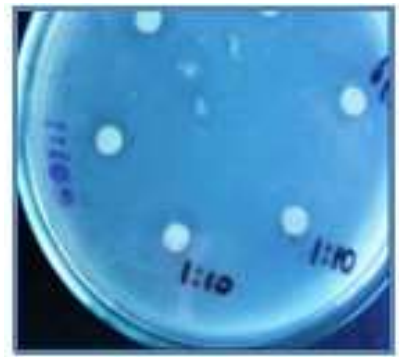

a

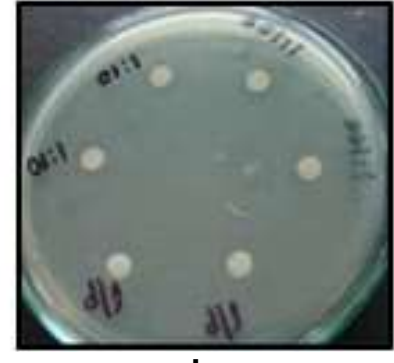

b

Figure 6. Zones of growth inhibition of Pseudomonas aeruginosa (bottom view) under the influence of the initial and diluted compositions after (a) 24 hours and (b) 4 days. $\mathrm{T}=35^{\circ} \mathrm{C}$.

The effect of the composition with variable concentration on the reproduction of two types of filamentous fungi is depicted in Figures 7 and 8. The studied composition had fungicidal impact on test cultures of Cladosporium sphaerospermum and Fusarium oxysporum during the first 3-5 days of cultivation (Figure 7 a, Figure 8 b, c).

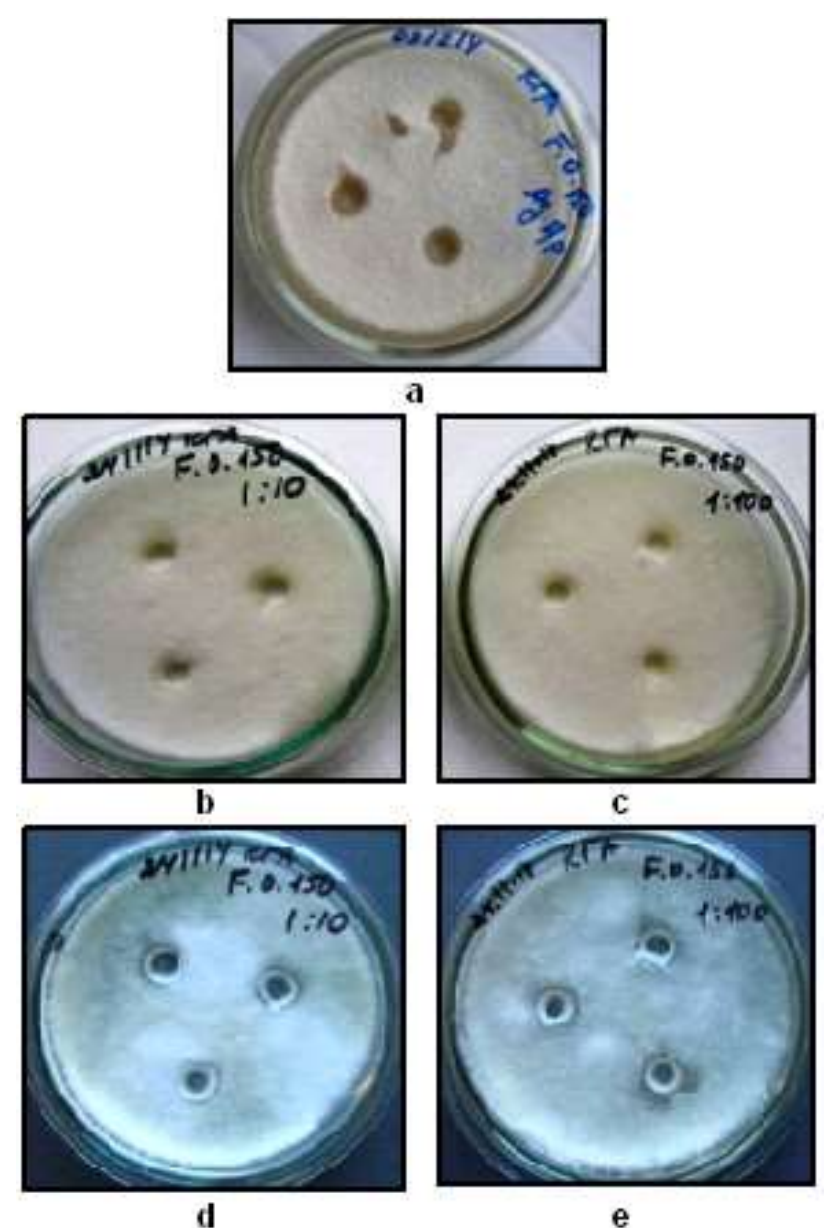

Figure 8. Zones of growth inhibition of Fusarium oxysporum under the influence of (a) the initial composition and diluted $(\mathbf{b}, \mathbf{c}) 10$ and $(\mathbf{d}, \mathbf{e}) 100$ times that were observed for $(\mathbf{b}, \mathbf{c}) 5$ and $(\mathbf{d}, \mathbf{e}) 18$ days. Top view (a) and bottom (b-e) are shown. $\mathrm{T}=28{ }^{\circ} \mathrm{C}$. 
At the same time, the same composition demonstrated only fungistatic effect in relation to filamentous Aspergillus ustus fungi (these data are not shown). It should be noted that the fungicidal and fungistatic action of the composition on Fusarium oxysporum fungi was stable and prolonged, since it manifested itself as zones of inhibition and further growth retardation for 30 days.

In experiments with test cultures of Candida albicans yeast, only the biostatic action of the composition with AgNPs was recorded. Here we observed only zones of growth retardation in which the growth rate of the yeasts decreased.

It is also important to note that the biocidal and biostatic effect of the composition diluted 10 and 100 times turned out to be brighter practically in almost all experiments.

The results of similar microbiological experiments with pieces of cotton fabric that were treated with compositions with different AgNP content are shown in Figures 9-14. In these cases, aqueous solutions of the original composition with $\mathrm{C}_{\mathrm{AgNP}}=1.2 \cdot 10^{-2} \mathrm{~kg} \cdot \mathrm{m}^{-3}$ and its three dilutions: $1: 10,1: 100$, and even 1:1000 were used. Moreover, two additional types of fungi, namely Penicillium variabile and Exophiala alcalophila, were used as test cultures. Three examples of the biocidal effect of the composition on the bacteria Staphylococcus aureus and Pseudomonas aeruginosa are shown in Figure 9.

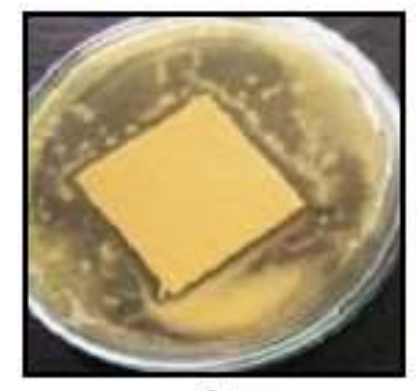

a

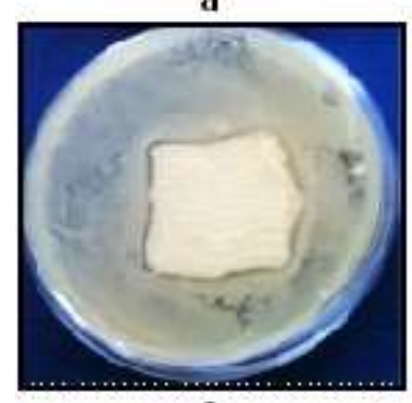

C
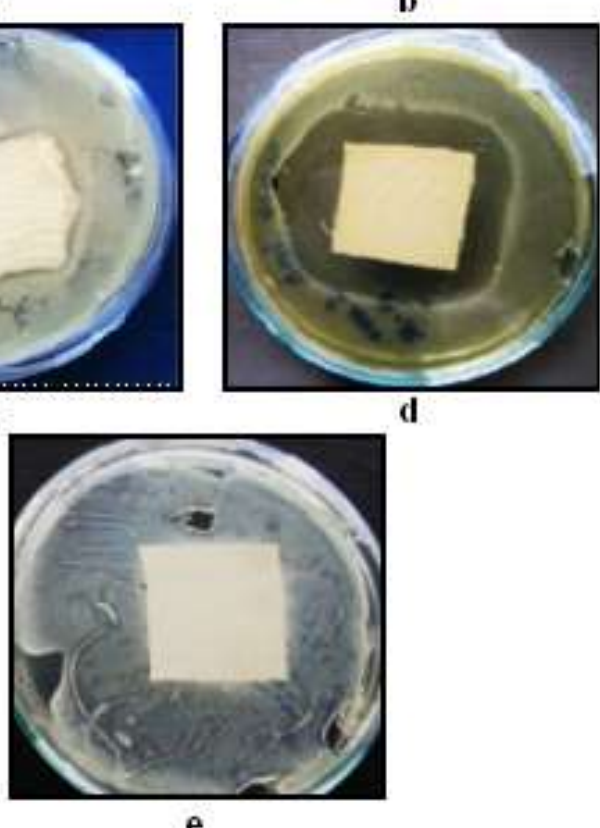

d

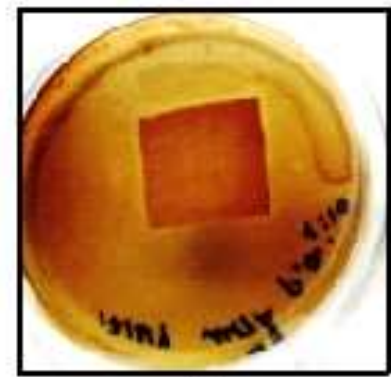

b

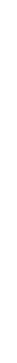

Figure 9. Zones of growth inhibition of bacteria (a, c-e) Staphylococcus aureus and (b) Pseudomonas aeruginosa under the action of a composition diluted (b) 10, (a) 100 and (c) 1000 times, (d) benzalconium chloride with $\mathrm{C}=30$ $\mathrm{kg} \mathrm{m}^{-3}$ and (e) sterile water after 3 days. $\mathrm{T}=35^{\circ} \mathrm{C}$.

Zones of growth inhibition of 2.7-3.3 $\mathrm{mm}$ remained around the tissues treated with compositions in which the concentration of AgNPs varied in a very wide range from $\mathrm{C}_{\mathrm{AgNPs}}=1.2 \cdot 10^{-2}$ to $1.2 \cdot 10^{-5} \mathrm{~kg} \cdot \mathrm{m}^{-3}$ (Figure 9 ac). Similar zones were $9-11 \mathrm{~mm}$ in the case of cotton fabric treated with the well-known biocidal agent benzalkonium chloride with a significantly higher concentration $\left(C=30 \mathrm{~kg} \mathrm{~m}^{-3}\right)$ of the active substance (Figure 9 d). In contrast, zones of growth inhibition of microorganisms 
were absent in the control variant (Figure 9 e), when the fabric fragments were moistened with sterile water only.

The following examples relate to the effect of AgNPs/PIH compositions on different fungi. The width of the growth inhibition zones appearing around tissue fragments varied from 2 to $6.5 \mathrm{~mm}$ for dark pigmented fungi, such as Cladosporium sphaerospermum (Figure 10 a, b) and Exophiala alcalophila (Figure 11).

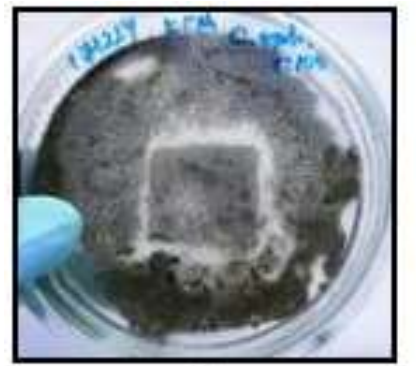

a

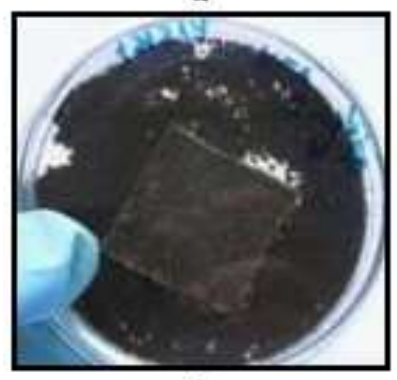

c

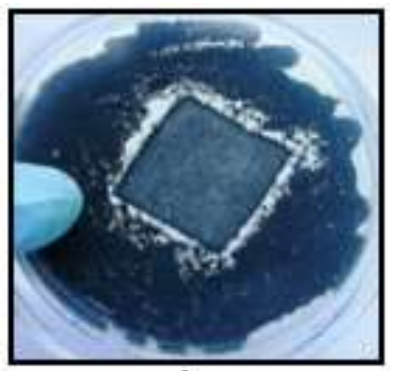

b

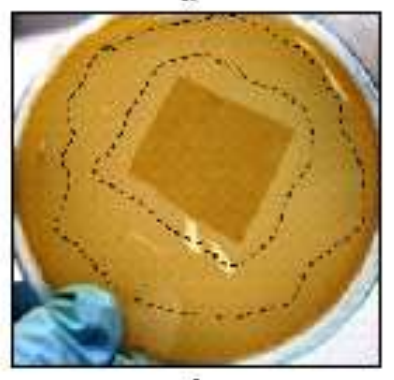

d
Figure 10. Zones of growth inhibition of fungi (a-c) Cladosporium sphaerospermum and (d) Candida albicans under the action of a composition diluted (d) 10, (a) 100 and (b) 1000 times, and (c) sterile water after 3 days. $\mathrm{T}=28(\mathbf{a}-\mathbf{c})$ and $35^{\circ} \mathrm{C}(\mathbf{d})$.

The effect of the composition on the yeast-like fungi of Candida albicans was expressed in the formation of a large zone of growth inhibition (14-27 mm) after 2 days. But this zone decreased to $2.5-7 \mathrm{~mm}$ after 3 days (Figure $10 \mathrm{~d}$ ). In the control variant (Figure 10 c), the cotton fabric was completely overgrown with mycelium of fungal test cultures.

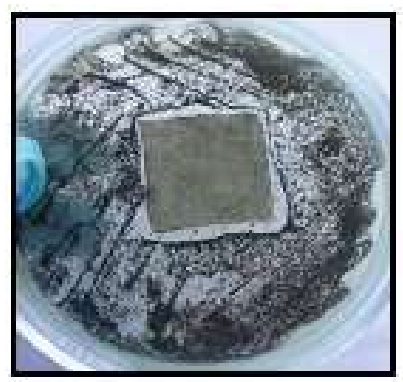

a

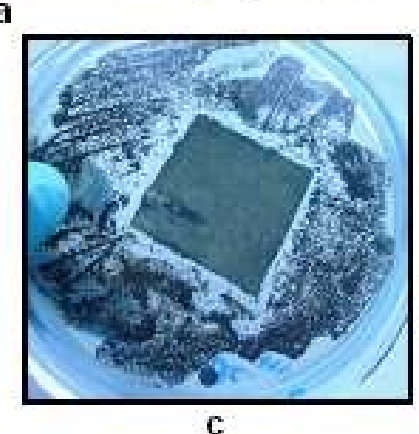

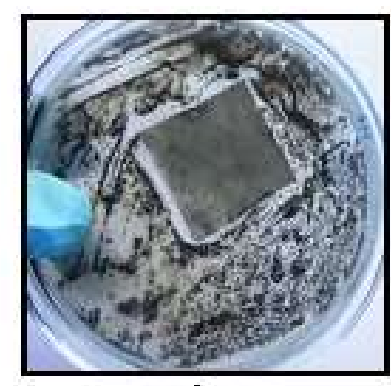

b
Figure 11. Zones of growth inhibition of Exophiala alcalophila fungus under the action of a composition diluted (a) 10, (b) 100 and (c) 1000 times after 3 days. $\mathrm{T}=28^{\circ} \mathrm{C}$.

The growth inhibition zones were 3-6 $\mathrm{mm}, 2-4 \mathrm{~mm}$, and $1.5-2 \mathrm{~mm}$ wide for lightpigmented filamentous fungi Fusarium oxysporum, Penicillium variabile and Aspergillus ustus (Figures 12 a, 13, 14, respectively). But the same zones were equal to 4-7 mm for Fusarium oxysporum when cotton fabric was treated with a biocide agent benzalkonium chloride having significantly higher concentration $\left(\mathrm{C}=30 \mathrm{~kg} \cdot \mathrm{m}^{-3}\right)$ of active substance (Figure 12 b). Finally, the zones of growth inhibition of Fusarium oxysporum turned out to be fully absent in the control test (Figure 12 c), in which the fabric fragment was moistened with sterile water.

It should also be noted that in these 
experiments, the formation of only separate colonies of the tested cultures of microscopic fungi was observed in zones of growth inhibition (Figures 10 a, b; 11, 13, 14).

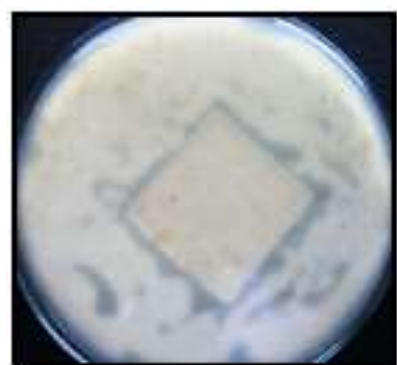

a

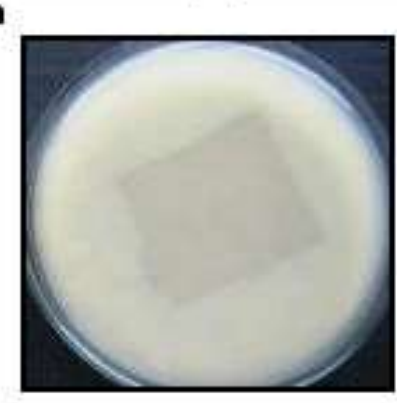

C

Figure 12. Zones of growth inhibition of Fusarium oxysporum fungus under the effect of (a) a composition diluted 10 times, (b) benzalkonium chloride with $\mathrm{C}=30 \mathrm{~kg}$ $\mathrm{m}^{-3}$ and (c) sterile water after 3 days. $\mathrm{T}=28{ }^{\circ} \mathrm{C}$.

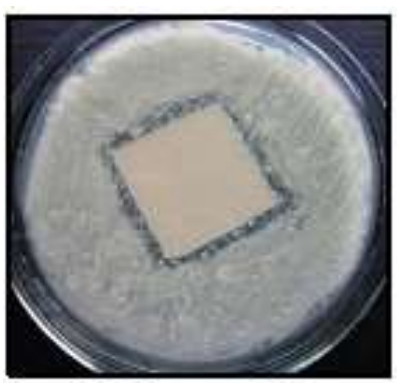

a

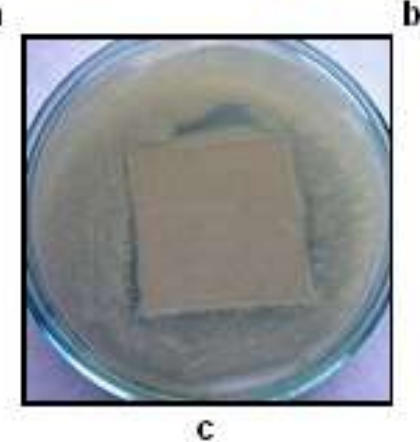

Figure 13. Zones of growth inhibition of Penicillium variabile fungus under the action of a composition diluted (a) 10 , (b) 100 and (c) 1000 times after 3 days. $\mathrm{T}=28^{\circ} \mathrm{C}$.
The described action of the AgNPs/PIH composition, with which the pieces of cotton fabric were processed, was evaluated as fungistatic. The test culture of Candida albicans was found to be the most sensitive to the effects of the composition in these experiments, while the culture of Aspergillus ustus turned out to be the most stable. It is also important to emphasize that the biostatic effect of the AgNPs/PIH composition, diluted 10 and 100 times, turned out to be more vivid in almost all tests, both using the disc method and using cotton fabric.

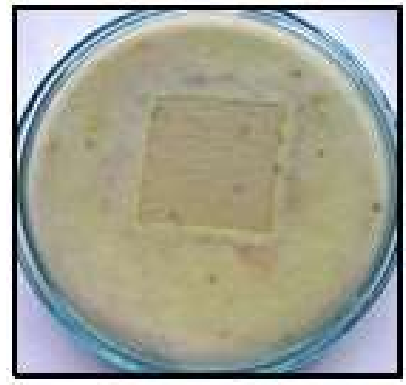

a

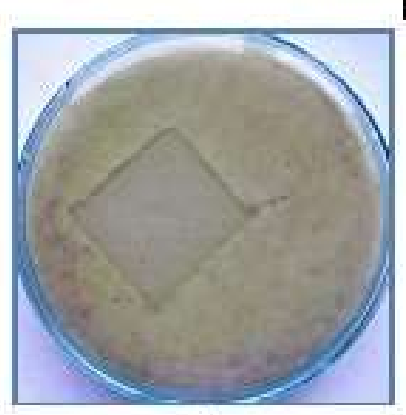

c

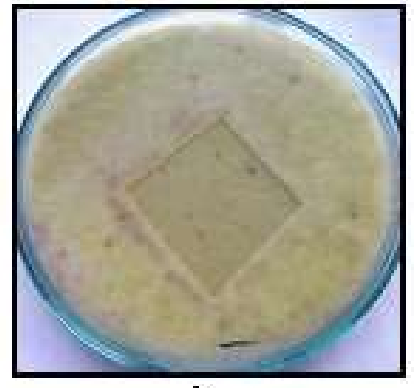

b

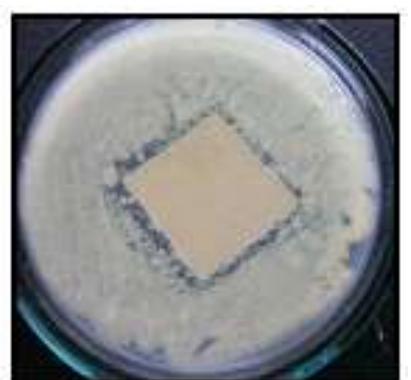

b
Figure 14. Zones of growth inhibition of Aspergillus ustus fungus under the action of a composition diluted (a) 10, (b) 100 and (c) 1000 times after 3 days. $\mathrm{T}=28^{\circ} \mathrm{C}$.

The results of these experiments confirmed the stable and long-lasting bactericide and fungistatic action of the AgNPs/ PIH composition applied to cotton fabric in a very wide concentration range. This opens up 
prospects for its successful application as a new biocidal preparation for the treatment and longterm disinfection of wound dressings and hygienic materials such as bandages, gauze, wipes, plasters and so on.

An important aspect of the use of biocidal preparations for the impregnation of dressings is their interaction with open wounds and the possible impact on the rate of wound healing. There are relatively few studies devoted to this subject; in addition, their results are often contradictory. For example, a significant reduction in the healing time and an increase in bacterial clearance from infected wounds was observed in a study [54] using wound dressings soaked with AgNPs compared to silver sulfadiazine solution. But in another study [55], wound dressings loaded with AgNPs increased the healing time of superficial burn wounds but showed no difference in the healing of deep burn wounds, compared with silver sulfadiazine.

To clarify this aspect in our case, we studied the healing process of open wounds $(10 \times 10 \mathrm{~mm})$ in rats that were treated with some agents, primarily the composition of $\mathrm{AgNPs} / \mathrm{PIH}$ (in the 2nd group of rats), as well as Carbopol and EM for a comparison (in the 3rd and 4th groups of animals). The 1st group of rats was control. Changes in time in the area of the wounds of rats are presented in Table 2.

We analyzed these data from different points of view. In the case of comparing the total number of days during which complete
Table 2. Effect of different agents on wound healing

\begin{tabular}{|c|c|c|c|c|}
\hline \multirow{2}{*}{ Days } & \multicolumn{4}{|c|}{ The average wound area $(\mathrm{n}=10), \mathrm{mm}^{2}$} \\
\cline { 2 - 5 } & $\begin{array}{c}1 \text { st } \\
\text { group }\end{array}$ & $\begin{array}{c}\text { 2nd } \\
\text { group }\end{array}$ & $\begin{array}{c}\text { 3rd } \\
\text { group }\end{array}$ & $\begin{array}{c}4 \text { th } \\
\text { group }\end{array}$ \\
\cline { 2 - 5 } & Control & AgNPs/PIH & Carbopol & EM \\
\hline 0 & $100_{ \pm 3}$ & $100_{ \pm 4}$ & $100_{ \pm 3}$ & $100_{ \pm 3}$ \\
\hline 3 & $153_{ \pm 21}$ & $100_{ \pm 1}$ & $129_{ \pm 14}$ & $187_{ \pm 36}$ \\
\hline 6 & $111_{ \pm 5}$ & $50_{ \pm 1}$ & $11_{ \pm 5}$ & $127_{ \pm 12}$ \\
\hline 9 & $99_{ \pm 4}$ & $37_{ \pm 1}$ & $76_{ \pm 3}$ & $71_{ \pm 7}$ \\
\hline 14 & $54_{ \pm 1}$ & $6_{<1}$ & $71_{ \pm 3}$ & $36_{ \pm 3}$ \\
\hline 19 & $23_{ \pm 1}$ & 5 & $54_{ \pm 1}$ & 0 \\
\hline 22 & 0 & $3_{<1}$ & $30_{<1}$ & \\
\hline 25 & & 0 & 0 & \\
\hline
\end{tabular}

healing of the wounds took place, the best result ( $\sim 19$ days) was observed in the 4th group of rats, for the treatment of which an EM solution was used. This time was 4 days shorter compared to the time of complete wound healing in the 1st control group of animals. The time of complete wound healing in the 2 nd and 3rd groups of rats when using the $\mathrm{AgNPs} / \mathrm{PIH}$ composition and the Carbopol preparation was approximately the same ( $\sim 25$ days) and was higher than in the control group ( $\sim 22$ days).

But the picture will be different if we compare the healing processes of wounds that were treated with various preparations. From such point of view, the effect of EM on open wounds in the 4th group of rats was the most severe among all the investigated agents, because this drug caused the strongest 
additional inflammation of the wounds during first 3 days, which led to a 2-fold increase in the area of the wounds. More clearly, this fact is evident from Figure 15. This effect was even 1.2 times higher than inflammation of wounds that were not treated with any agents (in the control group).

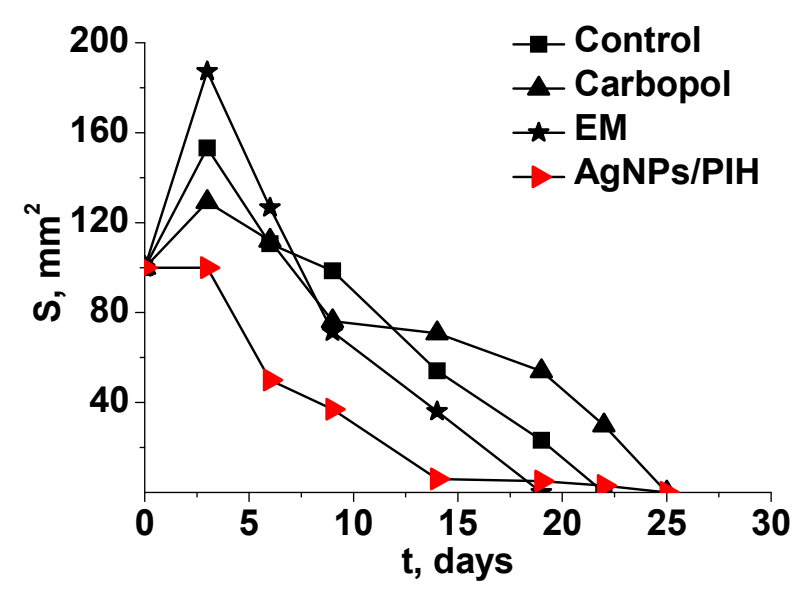

Figure 15. The dynamics of reducing the average area of wounds in rats under the influence of various drugs.

The drug Carbopol also caused mild inflammation of the wounds, which was expressed in an increase in S area by $29 \%$ during the first 3 days in the 3 rd group of rats. On the contrary, the effect of the AgNPs/PIH composition was the most tolerant of open wounds (in the 2nd group of rats), since it did not cause any inflammation of the wounds during the first 3 days and contributed to their rapid healing over the next 11 days (Figure 15). As a result, the condition of wounds treated with our composition on the 14th day was the best $\left(\mathrm{S}=6 \mathrm{~mm}^{2}\right)$ compared to wounds treated with other drugs $\left(\mathrm{S}=36\right.$ and $71 \mathrm{~mm}^{2}$ for $E M$ and Carbopol, respectively) or not treated at all
$\left(\mathrm{S}=54 \mathrm{~mm}^{2}\right)$.

The next important question is the preparation efficacy, which is determined by the concentration of the active substance in the solution used to treat wounds. From this point of view, the AgNPs/PIH composition was more effective in the wound healing process than the EM solution. This is confirmed by a significantly lower concentration (more than 83 times) of active AgNPs compared to EM in solution.

Thus, the developed biocide composition has shown high efficiency in wound healing. It did not cause any inflammation of the wounds during the first 3 days, and then acted quickly and confidently, leaving only small traces $(\sim 6$ $\mathrm{mm}^{2}$ ) from the original wounds $\left(100 \mathrm{~mm}^{2}\right)$ on day 14. In addition, the positive effect of this composition takes place at a very low concentration of active silver nanoparticles.

In the last decade, the achievements of nanotechnologies have been actively introduced in agriculture, in particular, in the practice of growing agricultural plants [56]. One of the promising directions in this area is the synthesis and delivery of biogenic metal nanoparticles ( $\mathrm{Co}, \mathrm{Cu}, \mathrm{Fe}, \mathrm{Mn}, \mathrm{Mg}, \mathrm{Zn}$, etc.) or their oxides into plants to stimulate their growth and combat plant diseases [57]. The ions of biogenic metals in small doses contribute to the growth and development of plants, but in large doses they poison both plants and the environment [58]. Therefore, the fruitful idea appeared to use 
stabilized aqueous dispersions or powders of metal nanoparticles instead of their salts or chelates for seed treatment and/or foliar treatment of growing plants $[13,14]$.

Metal nanoparticles have less toxicity, but exhibit a complex effect: as small particles with a developed surface that interact with various cells and components of plants, as sources of active metal ions with controlled release over time and as biocidal agents that protect plants and soil from pathogenic bacteria, fungi and viruses. At the same time, the mechanism and effectiveness of the action of metallic nanoparticles on specific plants remain poorly understood.

There are only few publications devoted to the effect of AgNPs on various agricultural plants such as rice, corn, beans, pumpkin, spring wheat, peas, and radish [14]. Especially few studies describe such investigations conducted in the fields under real atmospheric conditions [57]. These studies have clearly shown that AgNPs can have different and significant effects on morphology, physiology, biochemistry and yield of plants. The final effect depends on the size, properties and concentration of nanoparticles, the methodology of their introduction (by treating the seeds or leaves of plants or through the soil), as well as on the nature of plants [14].

In the present work, we carried out presowing treatment of winter wheat seeds with the developed AgNPs/PIH composition (Figure 3) with the initial concentration (1:1) and diluted 10 times (1:10). Each portion of the treated seeds of $50 \mathrm{~kg}$ was sown on 0.4 acres of field. For this, a total of $250 \mathrm{~cm}^{3}$ of composition with $\mathrm{C}_{\mathrm{AgNPs}}=1.2 \cdot 10^{-2} \mathrm{~kg} \cdot \mathrm{m}^{-3}$ was required. Also for comparison, two plots of the same field of 0.4 acres each were sown with untreated winter wheat seeds. All mentioned areas of this field are shown in Figure 16 a.

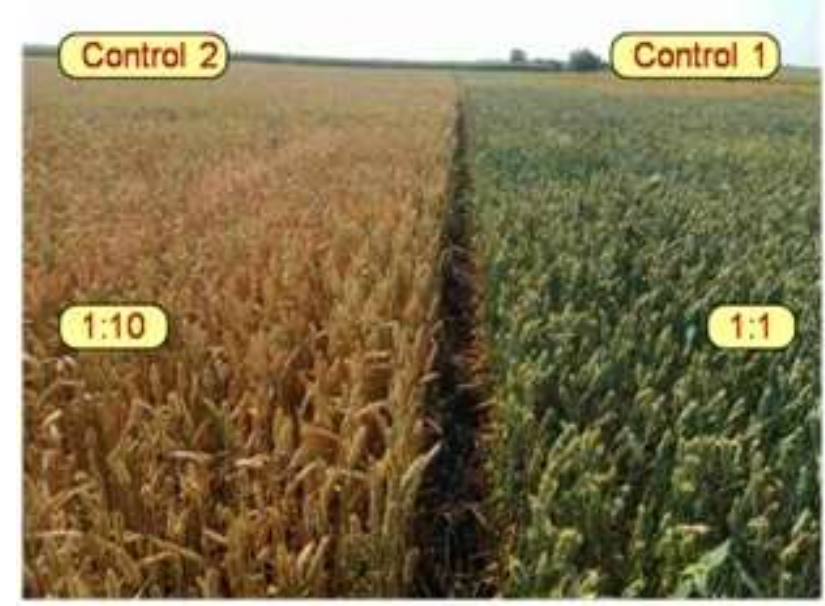

a

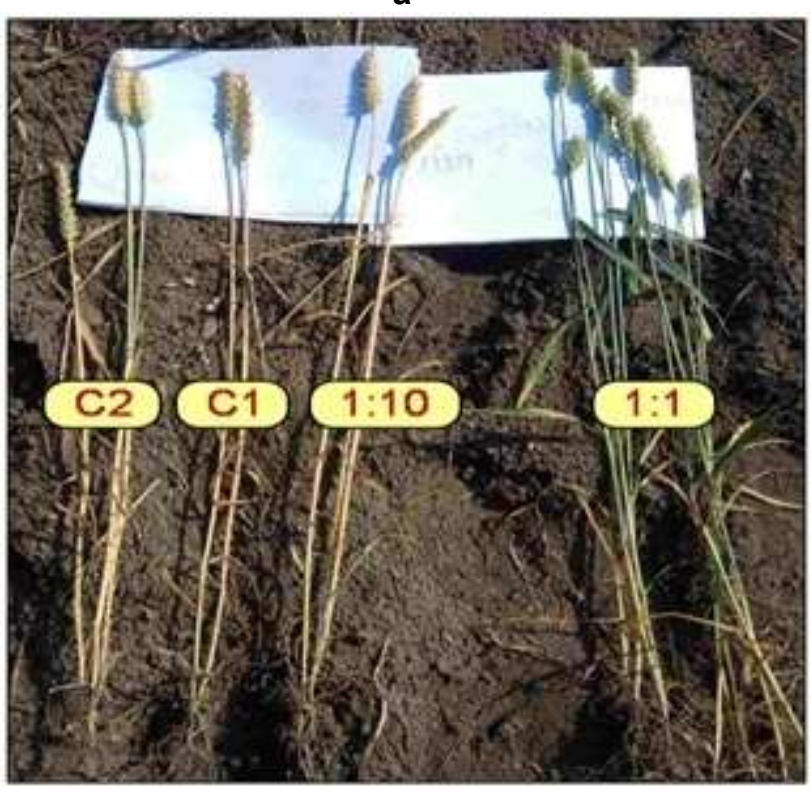

b

Figure 16. Photos show: (a) two experimental (near) and control (remote) sections of the winter wheat field and (b) several separate plants from these areas. 
First of all, a significant difference was observed in the color of winter wheat plants (yellow compared to green) grown from untreated seeds or treated with a diluted composition of 1:10 (Control 1 and Control 2 areas and the left near area in Figure 16 a) and seeds treated with the original composition 1:1 (the right near area in Figure 16 a). At the same time, we observed the absence of a noticeable effect of the composition on the speed and degree of seed germination and the length of plant stems, while the size of spikelets in plants grown from seeds treated with an undiluted composition was slightly smaller (Figure 16 b). These interesting and vivid facts indicated an increase in the vegetation period of winter wheat plants under the influence of a composition with a sufficiently high concentration of AgNPs.

\section{Conclusions}

Thus, the obtained polymer/inorganic hybrid based on small silica "cores" and long polyacrylamide grafts formed compact particles of 6-18 $\mathrm{nm}$ in an aqueous medium due to partial adsorption of covalently-bound polymer chains on the surface of $\mathrm{SiO}_{2}$ and additional binding of the nearest PAAm segments in the grafted layer. These particles demonstrated strong aggregation in solution due to the interaction between the grafted layers of various hybrid particles, which led to the appearance of fractal clusters of variable sizes and shapes. It was shown that the in situ synthesis of AgNPs in PIH solutions developed mainly in the grafted PAAm chains and was accompanied by the destruction of clusters and swelling of hybrid nanoparticles. As a result, the final $\mathrm{AgNPs} / \mathrm{PIH}$ composition can be represented as a set of discrete swollen $\mathrm{PIH}$ particles with a size of $\sim 10-40 \mathrm{~nm}$, containing one or several silver nanoparticles with a size of 3-9 $\mathrm{nm}$.

A series of microbiological tests carried out using both the disc method and pieces of cotton fabric showed a stable and long-lasting bactericidal effect of the composition on bacteria of the genera Staphylococcus and Pseudomonas, as well as fungistatic effect on yeast of the genus Candida and filamentous fungi of the genera Aspergillus, Cladosporium, Penicillium, Exophiala, and Fusarium in a very wide range of concentrations. These properties have been successfully combined with the high efficacy of the composition in wound healing of rats. Indeed, its use did not cause additional inflammation of the wounds in the first 3 days, and subsequently contributed to their accelerated healing. In addition, a positive effect was achieved at very low concentrations of active AgNPs. All these results allow us to consider the AgNPs/PIH composition as a new promising biocidal preparation for the treatment and long-term disinfection of wound dressings and hygienic materials such as bandages, gauze, wipes, plasters and so on.

Our initial studies of the effect of the composition on the growth and development of 
winter wheat (during pre-sowing seed treatment) allow us to record only the interesting fact of a significant extension of the vegetation period of this plant. But in order to establish the causes of this phenomenon and identify the positive and possible negative aspects of its practical application, further research is needed.

\section{Acknowledgements}

The authors are grateful for the basic financial support provided by Taras Shevchenko National University of Kyiv. In addition, these studies were also partially supported by the Institutes of Botany and Macromolecular Chemistry of the National Academy of Sciences of Ukraine, as well as the Scientific-Reseach Center of "Kernel".

\section{References}

[1] Denyer SP, Hugo WB (Eds.), Mechanisms of action of chemical biocides. Their study and exploitation. Oxford, UK: BLACKWELL SCIENTIFIC PUBLICATIONS; 1991, 346 pp.

[2] Gilbert P, McBain AJ, Potential impact of increased use of biocides in consumer products on prevalence of antibiotic resistance. Clin. Microbiol. Rev 2003;16(2):189-208.

[3] European Commission, Health \& Consumer Protection DG, SCENIHR (Scientific Commettee on Emerging and Newly Identified Health Risks), Assessment of the antibiotic resistance effects of biocides, 19 January 2009, 87 pp.

[4] Bobbarala V (Ed.), A search for antibacterial agents. Rijeka, Croatia: INTECH; 2012, 344 pp.

[5] Simoncic B, Tomsic B, Structures of novel antimicrobial agents for textiles - a review. Textile Res. J. 2010; 80(16):1721-1737.
[6] Sakharov SP, Kozlov LB, Ivanov VV, Analysis of the microbial landscape of wound infection with severe thermal injury in children. Fundamental Res. 2013; 9(3):468-471 (in Russian).

[7] Hoog GS de, Guarro J, Atlas of clinical fungi. Utrecht, The Netherlands: Electronic Version 3.1, 2011 (www. clinicalfungi.org).

[8] Huh AJ, Kwon YJ, "Nanoantibiotics": A new paradigm for treating infectious diseases using nanomaterials in the antibiotics resistant era. J. Control. Release. 2011;156:128-145.

[9] Ray M, Yadav A, Gade A. Silver nanoparticles as a new generation of antimicrobeals. Biotechnol. Adv. 2009;27:76-83.

[10] Domènech $B$, Muñoz $M$, Muraviev DN, Macanás J, Polymer-silver nanocomposites as antibacterial materials. In: Méndez-Vilas A, editor. Microbial pathogens and strategies for combating them: science, technology and education. Badajoz: Formatex; 2013, p. 630-640.

[11] Murphy M, Ting K, Zhang X, Soo C, Zheng $Z$, Current development of silver nanoparticle preparation, investigation, and application in the field of medicine. J. Nanomaterials. Hindawi Publ. Corp. 2015:696918 (12 pp)

[12] Ravishankar RV, Jamuna BA, Nanoparticles and their potential application as antimicrobials. In: Méndez-Vilas A, editor. Science against microbial pathogens: communicating current research and technological advances. Badajoz: Formatex; 2011, p. 197209.

[13] Morales-Díaz AB, Ortega-Ortíz H, JuárezMaldonado A, Cadenas-Pliego G, Susana GonzálezMorales S, Benavides-Mendoza A, Application of nanoelements in plant nutrition and its impact in ecosystems. Adv. Nat. Sci.: Nanosci. Nanotechnol. 2017;8:013001-013014.

[14] Rastogi A, Zivcak M, Sytar O, Kalaji HM, He X, Mbarki S, Brestic M, Impact of metal and metal oxide nanoparticles on plant: a critical review. Frontiers in Chemistry 2017;5:Art.78 (16 pp). 
[15] Siddiqui MH, Al-Whaibi MH, AlKhaishany MF and MY, Role of nanoparticles in plants. In: Siddiqui MH et al. editors. Nanotechnology and plant sciences. Switzerland: Springer International Publishing; 2015, p. $19-35$

[16] Pulit-Prociak J, Banach M, Silver nanoparticles - a material of the future...? Open Chem. 2016;14:76-91

[17] Tran QH, Nguyen VQ, Le A-T, Silver nanoparticles: synthesis, properties, toxicology, application and perspectives. Adv. Nat. Sci.: Nanosci. Nanotechnol. 2013;4:033001 (20 pp)

[18] Korbekandi H, Iravani S, Silver nanoparticles. In: Hashim AA editor. The delivery of nanoparticles. Iran: InTech; 2012, p. 3-36

[19] Reidy B, Haase A, Luch A, Dawson KA, Lynch I, Mechanisms of silver nanoparticle release, transformation and toxicity: a critical review of current knowledge and recommendations for future studies and applications. Materials. 2013;6(6):2295-2350

[20] Kumar C, Nanomaterials - toxicity, health and environmental issues. Weinheim, Germany: WileyVCH Verlag GmbH \& Co; 2006; Vol. 5.

[21] AshaRani P.V., Prakash Hande M., Valiyaveettil S, Anti-proliferative activity of silver nanoparticles. BMC Cell Biology 2009;10:65 (14 pp)

[22] Morones JR, Elechiguerra JL, Camacho A, Holt K, Kouri JB, Ramirez JT, Yacaman MJ Nanotechnology 2005;16:2346-2353

[23] Pratsinis A, Hervella P, Leroux J-C, Platsinis SE, Satirioum GA, Toxicity of silver nanoparticles in macrophages. Small. 2013;9(15):25762584.

[24] Foldbjerg R, Olesen P, Hougaard M, Dang DA, Hoffmann HJ, Autrup H, PVP-coated silver nanoparticles and silver ions induce reactive oxygen species, apoptosis and necrosis in THP-1 monocytes. Toxicol. Lett. 2009;190(2):156-162

[25] Medina C, Santos-Martinez MJ, Radomski A, Corrigan OI, Radomski MW, Nanoparticles: pharmacological and toxicological significance. Br. J. Pharmacol. 2007;150:552-558

[26] Park MV, Neigh AM, Vermeulen JP, ... The effect of particle size on the cytotoxicity, inflammation, developmental toxicity and genotoxicity of silver nanoparticles. Biomaterials. 2011;32(36):98109817

[27] Kim T-H, Kim M, Park H-S, Shin US, Gong M-S, Kim H-W, Size-dependent cellular toxicity of silver nanoparticles. J. Biomed. Mater. Res. Part A. 2012;100A:1033-1043

[28] Greulich C, Diendorf J, Simon T, Eggeler G, Epple M, Koller M, Uptake and intracellular distribution of silver nanoparticles of human mesenchymal stem cells. Acta Biomater. 2011;7(1):347354

[29] Kennedy DC, Orts-Gil G, Lai C-H, Miller S, Haase A, Luch A, Seeberger PH, Carbohydrate functionalization of silver nanoparticles modulates cytotoxicity and sellular uprake. J. Nanobiotechnol. 2014;12:59 (8 pp)

[30] Wen Y, Geitner NK, Chen R, Ding F, Chen $\mathrm{P}$, Andorfer RE, Govindan PN, Ke PC, Binding of cytoskeletal proteins with silver nanoparticles. RSC Adv. 2013; (6 pp) DOI: 10.1039/c3ra43281e

[31] Li Y, Bhalli JA, Ding W, Yan J, Pearce MG, Sadiq R, Cunningham CK, Jones MY, Monroe WA, Howard PC, Zhou T, Chen T, Cytotoxicity and genotoxicity assessment of silver nanoparticles in mouse. Nanotoxicology. 2013; (10 pp) Informa UK Ltd, DOI: $10.3109 / 17435390.2013 .855827$

[32] Fedorchuk S, Zheltonozhskaya T, Gomza Yu, Kunitskaya L, Demchenko O, Synthesis of silver nanoparticles in the matrices of block and graft copolymers and polymer/inorganic hybrid in water solutions. Macromol. Symp. 2012;317-318(1):103-116

[33] Sojka RE, Bjorneberg DL, Entry JA, Lentz $\mathrm{RD}$, Orts $\mathrm{WJ}$, Polyacrylamide in agriculture and environment land management. Adv. Agronomy 2007; 92:75-162 
[34] Kaliammal P, Rosemary MJ, Khadar A, Synthesis, characterization and application of polymer protected silver and silver iodide nanoparticles. Indian J. Nanotechnol. Appl. 2013;1(1):49-60

[35] Islam MS, Molla MAI, Sarker M, Karim MM, Masum SM, Yeum JH, Fabrication of pllulan/silver nanoparticle composite nanospheres using electrospray technique for antibacterial applications. Int. J. Basic \& Appl. Sci. 2011;11(1):36-40

[36] Ghosh S, Ranebennur TK, Vasan HN, Study of antibacterial efficacy of hybrid chitosan-silver nanoparticles for prevention of specific biofilm and water purification. Int. J. Carbohydrate Chem. Hindawi Publ. Corp. 2011:693759 (11 pp)

[37] Palza H, Antimicrobeal polymers with metal nanoparticles. Int. J. Mol. Sci. 2015;16:2099-2116

[38] Damm C., Münstedt H, Roösch A, Longterm antimicrobial polyamide 6/silver-nanocomposites. J. Mater. Sci. 2007;42:6067-6073

[39] Frolov YuG, Dvoretskaya GA, Tarasov SB, Determination of thermodynamic parameters of silica sol by light scattering method. Colloid J. 1984;46(5):971-975 (in Russian)

[40] Iler RK. The chemistry of silica: solubility, polymerization, colloid and surface properties and biochemistry of silica. Wiley-Interscience; 1979, 896 pp.

[41] Abramova LI, Beiburdov TA, Grigoryan EP. Polyacrylamide. Moskow: Chemistry; 1992, 189 pp. (in Russian)

[42] Xiong B, Loss RD, Shields D, Pawlik T, Hochreiter R, Zydney AL, Kumar M, Polyacrylamide degradation and its implications in environmental systems. npj Clean Water. 2018;17 (9 pp), www.nature.com/npjcleanwater

[43] Chemical encyclopedia. V.3. Zolotov YuA editor. Moskow: Scientific edition "Great Russian encyclopedia"; 1992, p.601 (in Russian)

[44] Maltseva NN, Hain VS, Sodium borohydride: properties and application. Moscow: NAUKA; 1985, 207 pp (in Russian)
[45] Lipatov YuS, Shilov VV, Gomza YuP, Kruglyak NE, X-Ray diffraction methods for studying polymer systems. Kyiv: Nauk. Dumka; 1982, 296 pp (in Russian)

[46] Kondratyuk TO, Kondratyuk SY, Morgaienko OO, Khimich MV, Beregova TV, Ostapchenko LI, Pseudonadsoniella brunnea gen. et sp. nov. (Meripilaceae, Agaricomycotina), a new brown yeast-like fungus producing melanin from Antarctic; with notes on nomenclature and type confusion of Nadsoniella nigra Issatsch. Acta Botanica Hungarica 2015;57(3-4): 291-320

[47] Schweitzer A, Howell RC, Jiang Z, Bryan RA, Gerfen G, Chen CC, Mah D, Cahill S, Casadevall A, Dadachova E, Physico-chemical evaluation of rationally designed melanins as novel nature-inspired radioprotectors. PLoS One 2009;4:e7229

[48] Directive 2010/63/EU of the European Parliament and of the Council of 22 September 2010 as to protection of animals used for scientific purposes (2010) Special edition in Croatian. Chapter 15, 028: pp. 82-128, http://data.europa.eu/eli/dir/2010/63/oj.

[49] Evanoff DD, Chumanov J and G, Synthesis and optical properties of silver nanoparticles and arrays. Chem. Phys. Chem. 2005;6:221-1231

[50] Kelly KL, Coronado E, Zhao LL, Schatz GC, J. Phys. Chem. B. 2003;107:668-677

[51] Becturov EA, Kudaybergenov SE, Garmagambetova AK, Iskakov RM, Ibraeva JE, Shmakov SN, Polymer-protected metal nanoparticles. Almaty; 2010, $274 \mathrm{pp}$

[52] Zheltonozhskaya T, Permyakova N, Momot L, Intramolecular polycomplexes in block and graft copoplymers. Ch. 5. In: Khutoryanskiy VV, Staikos G editors. Hydrogen-Bonded Interpolymer Complexes: Formation, Structure and Applications. New JerseyLondon-Singapore etc.: World Scientific Publ. Co.; 2009. p. $85-153$

[53] Zheltonozhskaya T, Permyakova N, Eremenko B, Inter- and intramolecular polycomplexes in 
polydispersed colloidal systems. Ch. 8. In: Khutoryanskiy VV, Staikos G editors. Hydrogen-Bonded Interpolymer Complexes. Formation, Structure and Application. New Jersey-London-Singapore etc.: World Scientific Publ. Co.; 2009. p. 201-234

[54] Huang Y, Li X, Liao Z, Zhang G, Liu Q, Tang J, Peng Y, Liu X, Luo Q. A randomized comparative trial between Acticoat and SD-Ag in the treatment of residual burn wounds, including safety analysis. Burns. 2007;33(2):161-166.

[55] Chen J, Han CM, Lin XW, Tang ZJ, Su SJ, Effect of silver nanoparticle dressing on second degree burn wound. Zhonghua Wai Ke Za Zhi. 2006;44(1):50-52 (in Chinese)

[56] Kole C, Kumar DS (Eds), Plant nanotechnology: principles and practices. Switzerland: SPRINGER; 2016, 383 pp.

[57] Farooqui A, Tabassum H, Ahmad A, Mabood A, Ahmad A, Ahmad IF, Role of nanoparticles in growth and development of plants: a review. Int. J. Pharma Bio Sci. 2016;7(4):22-37

[58] Arif N, Yadav V, Singh S, Singh S, Ahmad P, Mishra RK, Sharma S, Tripathi DK, Dubey NK, Chauhan DK, Influence of high and low levels of plantbeneficial heavy metal ions on plant growth and development. Front. Environ. Sci. 2016;4:Art.69 (11 pp). 